\title{
A responsabilidade da empresa para além do contexto de saúde e segurança no meio ambiente de trabalho
}

\section{Company's responsibility beyond health and safety context in the work environment}

\author{
Diego Saimon de Souza Abrantes ${ }^{1 *}$ \\ ${ }^{1}$ Psicólogo/coach, palestrante, docente no Instituto Macapaense do Melhor Ensino Superior, Macapá, AP, Brasil. http://orcid.org/0000- \\ 0003-0175-8342 E-mail: diego_saimon@hotmail.com *autor para correspondência.
}

\author{
Palavras-chave \\ Meio ambiente de trabalho \\ Saúde e segurança no trabalho \\ CLT \\ Normas Regulamentadoras \\ Gestão
}

\section{Keywords}

Work environment Health and safety at Work CLT

Regulatory Standards Management

\begin{abstract}
Em qualquer ambiente de trabalho, há riscos para a saúde e vida do trabalhador, sendo que dependendo do atividade da empresa, os riscos podem ser mais ou menos elevados. A Consolidação das Leis do Trabalho (CLT), Constituição Federal (CF) e Código Civil (CC) apresentam as regras de observação obrigatória para preservação da saúde e segurança no trabalho. A CLT rege as normas regulamentadoras (NRs) que estabelecem detalhadamente as medidas a serem tomadas pela organização para garantir um ambiente saudável e seguro a seus funcionários. A CF argumenta sobre as definições e prerrogativas do meio ambiente de trabalho e o CC demonstra a responsabilidade social da empresa com seus empregados. Através de um estudo bibliográfico e documental, com análise e interpretação qualitativa e descritiva dos dados colhidos em resenhas, com base principalmente na legislação de trabalho, buscou-se debater a relação das exigências legais e a que é desenvolvida entre empregador e empregado, além das oportunidades que a empresa pode ter com tudo isso. De fato, percebeu-se que se a empresa se adequar devidamente às obrigações legais e unir isso a um plano de trabalho condizente com a gestão do negócio, ela é capaz de atender as prerrogativas de lei e de promover a qualidade de vida no trabalho gerando melhora na produção e redução de custos.
\end{abstract}

In any work environment, there are risks to the health and life of the worker, and depending on the company's activity, the risks may be more or less high. The Consolidation of Labor Laws (CLT), Federal Constitution (CF) and Civil Code (CC) present the rules of mandatory observation for the preservation of health and safety at work. The CLT governs the NRs that set out in detail the measures to be taken by the organization to ensure a healthy and safe environment for its employees, the CF argues about the definitions and prerogatives of the work environment and the CC demonstrates the company's social responsibility with your employees. Through a bibliographic and documentary study, based mainly on labor legislation, we sought to discuss the relationship between legal requirements and that developed between employer and employee and opportunities that the company can have with all of this. In fact, it was realized that if the company duly complies with legal obligations and joins this to a work plan consistent with the management of the business, it is able, in addition to meeting the prerogatives of the law, to promote quality of life in the work generating improvement in production and cost reduction.

\section{INTRODUÇÃO}

A responsabilidade civil dentro do meio ambiente de trabalho, ensejado na área de segurança no trabalho, é tema crescente em discussões sobre o direito do trabalhador. Cresce, também, a fiscalização por parte dos órgãos públicos quanto ao respeito às normas de segurança nas empresas públicas e privadas e é possível notar, inclusive, como cursos voltados a esta temática tem se multiplicado.

Tudo isso ocorre sob o intuito de se resguardar a vida do trabalhador e se evitar acúmulo de ações trabalhistas, que partem do mesmo para com a empresa em casos de acidentes, doença incurável e sequelas referentes à atividade laborais, evidenciando, provavelmente, o desrespeito às normas de saúde e segurança. É fato que se tais coisas ocorrem, entra-se no âmbito da responsabilidade civil da empresa para com o profissional vitimado.

No Brasil, a Consolidação das Leis Trabalhistas (CLT) (BRASIL, 1943) é tida como marco importante para garantia de direitos ao trabalhador, isto porque ela visa regular todo o processo de trabalho que tramita na relação entre empregado e empregador. Dois anos antes dela, foi criada a justiça do trabalho, tendo a CLT sido criada em 1943 e esta última em 1941. Ambas faziam parte do planejamento do 
governo de Getúlio Vargas, na Era conhecida como Estado Novo, onde se buscava avanços nos diretos sociais brasileiros e o desenvolvimento da economia industrial do país (CEREZO, 2007).

Alguns estudiosos podem considerar a CLT antiquada e alegar necessidade de se atualizá-la. Esta discussão não cabe neste momento, mas ela existe e é de pertinência. Não importa o valor que se atribua a ela hoje, pois o válido é a mudança significativa que ela trouxe para as relações trabalhistas. A saúde e segurança do trabalhador está em seu bojo e explicita as obrigações que as empresas têm para com seus empregados.

Busca-se, nesta pesquisa, o debate da responsabilidade social da empresa para com seu funcionário, a fim de garantir a prevenção e promoção da saúde e segurança em seu meio ambiente interno, valorizando a relação de empregador e empregado e as oportunidades que isso pode gerar para a própria empresa. Para tanto, fez-se uso de uma pesquisa bibliográfica e documental que é aquela em que se faz a utilização de fontes científicas publicadas em livros, periódicos, revistas, jornais, documentos, neste caso, legislações (GIL, 2014). Tal definição é ratificada por Martins e Lintz (2011) quando eles afirmam que essas são as ferramentas do método bibliográfico, além da necessidade com o cuidado de escolha do material a ser considerados para a pesquisa, optando-se por fontes confiáveis e de respeito no âmbito científico e acadêmico.

Foram utilizados materiais científicos e documentais em atualização com as leis referentes à CLT, Constituição Federal de 1988 (CF) e o Código Civil (CC). Artigos e livros, disponíveis nas redes Scielo e Portal Capes, foram incluídos a partir das palavras-chaves: trabalho; meio ambiente de trabalho; responsabilidade civil; normas regulamentadoras; acidentes de trabalho; saúde no trabalho; segurança no trabalho. Livros de divulgação, isto é, publicações que exploram assuntos sistematicamente (GIL, 2014) foram escolhidos a partir dos títulos e sinopse que demonstravam relação direta com os objetos de estudos deste estudo. Os conteúdos sem esses indicadores ou que trabalhavam outras legislações foram desconsiderados.

Com os dados coletados através de resenhas, isto é, análises críticas de cada obra e lei lida, fez-se a análise e interpretação qualitativa das informações, descrevendo-se os resultados encontrados a partir do método descritivo. Gil (2014) afirma que esse método permite que se apresente toda informação devidamente colhida e seja feita sua administração na resolução de problemáticas semelhantes.

Deste modo, percebeu-se que se a empresa se adequar devidamente às obrigações legais e unir isso a um plano de trabalho condizente com a gestão do negócio, ela é capaz, além de atender as prerrogativas de lei, de promover a qualidade de vida no trabalho gerando melhora na produção e redução de custos. Descreve-se esses achados nos tópicos a seguir.

\section{O MEIO AMBIENTE DE TRABALHO}

O meio ambiente está classificado em quatro tipos que se complementam: meio ambiente natural (fauna e flora), meio ambiente artificial (aquele construído pelo homem), meio ambiente cultural (aquele imbuído de cultura, valores, moralidade e ritos) e meio ambiente de trabalho (CHIUVITE, 2012). Essa classificação demonstra como é necessário que se garanta os direitos ambientais a todos envolvidos nas espécies citadas e que de certo modo elas não se separam. Melo, R. M. (2012, p. 240) explica que:

A lei no $6.938 / 81$ foi um marco histórico sobre o tema, definindo meio ambiente como o conjunto de condições, leis, influências e interações de ordem física, química e biológica, que permite, abriga e rege a vida em todas as suas formas (art. 3o, inciso I), o que está em harmonia com a Constituição Federal de 1988 que, no caput do art. 225, buscou tutelar todos os aspectos do meio ambiente (natural, artificial, cultural e do trabalho) afirmando que "todos têm direito ao meio ambiente ecologicamente equilibrado, bem de uso comum do povo e essencial à sadia qualidade de vida".

Assim, concentrar-se-á no foco do estudo, o ambiente de trabalho: importa-se salientar, também, que o texto constitucional prevê pontualmente o meio ambiente de trabalho em dois artigos (BRASIL, 1988):

Art. 70, XXII: redução dos riscos inerentes ao trabalho por meio de normas de saúde, higiene e segurança.

Art. 200, VIII: colaborar na proteção do meio ambiente, nele compreendido o do trabalho.

O meio ambiente de trabalho, como a própria denominação exalta, é tido como aquele meio ambiente, formado desde a estrutura do local, aos objetos, pessoas e atividades existentes ali, que possibilitam a labuta. Rocha (2002, p.83) reforça a definição proposta ao dizer que: 
O meio ambiente do trabalho pode ser entendido como o local onde ocorrem as relações de trabalho e onde são desenvolvidas as atividades laborais humanas. O meio ambiente do trabalho contempla as instalações físicas do local, incluindo ventilação, iluminação, ruídos, móveis, maquinário, etc. que devem conferir um ambiente ecologicamente equilibrado para a prestação laboral, garantindo a minimização da possibilidade de contato com agentes químicos, físicos ou biológicos que importem riscos à saúde do trabalhador.

Este espaço ambiental, reafirma-se, está previsto na legislação brasileira dentro do artigo 225 da CF (BRASIL, 1988) como uma das tipologias de espaços ambientais ecologicamente equilibrados. Torna-se, de certo modo, impossível separar a questão do meio ambiente de trabalho e tudo aquilo que o cerca, estando presente também a questão da saúde e segurança dos trabalhadores, afinal é nele que o profissional desempenhará suas funções colocando-se em risco (de qualquer nível e tipo) à sua própria vida (SIRVINSKAS, 2010).

"Nas situações comuns de trabalho, são frequentes os incidentes e acidentes de origem incompreensível [...], que transtornam e desestabilizam os trabalhadores mais experimentados" (DEJOURS, 2007, p. 28). Isto quer dizer que faz parte da realidade desse ambiente, possíveis acidentes que acarretem algum dano ao empregado. Por isso, é de responsabilidade da empresa tomar precauções quanto à tais acontecimentos. Diversas dessas medidas são apontadas por lei e de observância obrigatória para os empregadores, podendo o trabalhador, no caso de dano, gerar ação contra eles. Isto é previsto, explicitamente, no CC de 2002, art. 927 (BRASIL, 2002): "haverá obrigação de reparar o dano, independente de culpa nos casos especificados em lei, ou quando a atividade normalmente desenvolvida pelo autor do dano implicar, por sua natureza, risco para os direitos de outrem".

A CLT prevê uma série de normas que a empresa precisa adotar para evitar qualquer tipo de dano ao seu empregado em seu local de trabalho ou decorrente dele. Parte-se do Tribunal do Trabalho a prerrogativa de culpa ou não do empregador no caso da alegação do trabalhador de que sua empresa não respeita ou atende aos preceitos legais. Em alguns casos, por responsabilidade objetiva e por o empregador estar ciente que ao abrir um negócio automaticamente é gerado riscos para quem ali trabalha, o profissional lesado tem causa ganha e a empresa é responsabilizada pelo fato (GARCIA, 2014). Entretanto, esta pode se resguardar, de que esses acontecimentos ocorram em seu ambiente. Para isso, deve valer-se da correta aplicação das medidas de segurança interna.

\section{A CLT E AS RESPONSABILIDADES DO EMPREGADOR}

A CLT apresenta os direitos e deveres de empregados e empregadores nas instituições brasileiras, públicas ou privadas, e visa reger a relação entre esses elementos. De modo geral, o que interessou a esta pesquisa foram os princípios dos artigos inseridos nela pela portaria $\mathrm{n}$. 3.214/1978, que vão do art. 154 ao 159 (BRASIL, 1978). Tais artigos estão contidos no capítulo $\mathrm{V}$ da CLT e resumem todo o conteúdo detalhado nas Normas Regulamentadoras (NRs).

As NRs especificam as obrigações do empregador no trato com a saúde e segurança de seus trabalhadores. Formam seu bojo, 36 normas, que descrevem desde os cuidados preventivos de acidentes à minimização dos riscos deles, tudo relativo à responsabilidade da empresa com seus empregados (BRASIL, 1978). Garcia (2014, p. 27-28) fala que:

As Normas Regulamentadoras, relativas à segurança e medicina do trabalho são de observância obrigatória pelas empresas privadas e públicas e pelos órgãos públicos da administração direta e indireta bem como pelos poderes dos órgãos legislativo e judiciário que possuam empregados regidos pela CLT (NR 1, item 1.1).

As aplicações contidas nas Normas Regulamentadoras (NRs), aplicam-se no que couber, aos trabalhadores avulsos, às entidades ou empresas que the tomem o serviço e aos sindicatos representativos das respectivas categorias profissionais (NR 1, item 1.1.1).

Algumas delas são tratadas como básicas para qualquer empresário e de qualquer tipo de empresa, como os cuidados que se deve ter com a realização de exames médicos (NR 7), uso de Equipamento de Proteção Individual (EPI) (NR 6), Ergonomia (NR 17), proteção contra incêndios (NR 23), Comissão Interna de Prevenção de Acidentes (CIPA) (NR 5), Serviço Especializado em Segurança e Medicina do Trabalho (SESMT) (NR 4). Estas, em geral, são as NRs que incidem em empreendimentos de qualquer tamanho e espécie, salvo exceções previstas na própria lei.

"O empregador deve agir em conformidade com os preceitos constitucionais e infraconstitucionais de proteção à 
saúde física e mental do trabalhador" (MINARDI, 2010, p. 155). Por isso, mesmo uma pequena empresa precisa se adequar, diferente do que pensa o senso comum a respeito de segurança no trabalho, em que tais normas só seriam aplicáveis a empresas grandes e com atividades industriais, de construção civil, com produtos químicos e biológicos, e nas funções de segurança pública (polícias, bombeiros e exército).

Uma organização, por menor que seja, como um pequeno mercado, por exemplo, precisa atender a normas de segurança, afinal tem trabalhadores que se expõem a diversos riscos, como o operador de caixa que passa muito tempo sentado e na mesma posição, podendo desenvolver problemas de coluna ou o estoquista que carrega nos braços pacotes de produtos para reposição, podendo sofrer uma grave queda. Nas residências com empregadas domésticas, as NRs podem ser aplicadas, pois a funcionária fará uso de materiais de limpeza que, dependendo do produto e da quantidade podem trazer danos à saúde. Ao cozinhar, há o risco de sofrer queimaduras, ao lavar o chão com produtos que o deixam escorregadio, pode-se cair e sofrer algum dano na musculatura ou ossos. São exemplos de que o tema está no cotidiano de toda população, quando geralmente, esta nem se percebe inserida nele.

Em todos esses casos, a responsabilidade por garantir condições de trabalho sem incidência de risco ou com a menor possível é do empregador. É de responsabilidade do Ministério do Trabalho editar as NRs, enquanto as superintendências regionais devem fiscalizar, exigir o cumprimento das regras e impor penalidades (ABUD, 2014).

É indicado às empresas que componham seu pessoal com pelo menos um profissional de saúde e segurança no trabalho, como o técnico em segurança no trabalho, o engenheiro em segurança no trabalho, um enfermeiro do trabalho e um médico do trabalho. Dependendo dos riscos envolvidos no ambiente da labuta, a empresa é obrigada a manter no mínimo um trabalhador dos tipos citados. Isso irá depender do tipo de atividade desempenhada pela empresa e do mapa de risco identificado por ela e por órgãos fiscalizadores (BENATTI; NISHIDE, 2000).

O mapa de risco tem a função de mapear as áreas de possíveis acidentes dentro do local de trabalho, explicitando os níveis de risco por pequeno, médio e grande, além dos grupos: químico, físico, biológico, ergonômico e mecânico. É importante frisar que em qualquer meio ambiente de trabalho há riscos, porém, o mapa se faz obrigatório em empresas com formação da CIPA. Ressalva-se que esta deve ser formada no momento em que a empresa se enquadrar no que está disposto na NR 5, ou seja, dependendo da atividade dela e da quantidade de funcionários, ela deve, obrigatoriamente, formalizar a CIPA (GALON; MARZIALE;
SOUZA, 2011)

No entanto, o mapa de risco não precisa ser formado apenas com a CIPA. Ao pequeno empreendedor (que em geral não necessita da mesma na sua empresa devido ao seu tamanho e número de funcionários) pode e é aconselhável que contrate um especialista para desenhar a ferramenta, visto que ela tem a função objetiva de elucidar para os trabalhadores os riscos que eles correm ali dentro e a partir disso, desenvolver práticas que prevenção.

\section{AS MEDIDAS DIANTE DAS RESPONSABILIDADES DO EMPREGADOR}

Diante das exigências legais que permeiam a saúde e segurança no meio ambiente de trabalho, as empresas não tem a opção de não as seguir corretamente, colocando-se em risco de penalidades severas em caso contrário. A CLT, no art. 157, reza as atribuições que cabem à empresa seguir (BRASIL, 1943):

I. Cumprir e fazer cumprir as normas de segurança e medicina do trabalho;

II. Instruir empregados, através de ordens de serviço, quanto à precauções a tomar no sentido de evitar acidentes de trabalho ou doenças ocupacionais;

III. Adotar medidas que lhes sejam determinadas pelo órgão regional competente;

IV. Facilitar o exercício da fiscalização;

As empresas podem adotar medidas internas, além das legalmente exigidas, para reforçar as práticas de segurança e facilitar o desenvolvimento e a percepção de uma cultura organizacional mais segura do ponto de vista de acidentes e doenças do trabalho.

Parte das qualidades de um bom empreendedor se concentram em sua capacidade de assimilar os riscos inerentes ao seu negócio e isto inclui a temática desta pesquisa. Dentro dessas características, algumas práticas se tornam comum no ambiente organizacional, com o objetivo de melhorar as medidas de segurança e estabelecer o comportamento de cuidado e precaução em todos os processos envolvidos. Marras (2000, p. 253 apud MELO, F. A. O. et al, 2011, p. 76) entende que a administração estratégica de recursos humanos pratica intervenções na gestão de pessoal buscando a otimização dos resultados da empresa e a melhora da qualidade de seus talentos.

Não obstante, já se começa a trabalhar o comportamento de segurança no trabalho no recrutamento e seleção, pois já se busca um candidato com características básicas exigidas 
para a função pleiteada, visando-se contratar pessoas com a qualidade de serem prevenidas e cuidadosas em suas atividades arriscadas (CHIAVENATO, 1999). Por exemplo, em uma seleção para eletricista, ao se desenhar o cargo, se estabelece as habilidades desejadas que este profissional tenha e de antemão é possível estabelecer que o candidato seja responsável, cuidadoso, tenha conhecimento prévio de sistemas elétricos e nunca tenha sofrido um acidente de trabalho grave provocado por ele mesmo. A partir disso, já é possível excluir os candidatos que tenham provável comportamento destrutivo e que ocasionariam algum acidente, acarretando prejuízo pessoal, profissional e para a empresa.

A organização viável, do ponto de vista de recursos humanos, é aquela que não apenas capta e aplica seus recursos humanos adequadamente, mas também os mantêm na organização. A manutenção dos recursos humanos exige uma série de cuidados especiais, entre os quais sobressaem os planos de compensação monetária, de benefícios sociais, higiene e segurança do trabalho e de relações trabalhistas (CHIAVENATO, 2009, p. 10).

Em outra instância, há os treinamentos focados em segurança no trabalho, além dos exigidos pelas NRs. Um programa de treinamento contínuo pode ser muito desejável, em que o trabalho com segurança é ensinado em constância, além da realização continuada de campanhas e concursos internos. Estes últimos podem ser feitos tanto pela CIPA quanto pelos Recursos Humanos da empresa (RH). Em geral, o mais interessante seria os dois setores, tanto $\mathrm{RH}$ quanto CIPA, trabalharem em conjunto no desenvolvimento de projetos para fortalecer a cultura de saúde e segurança no trabalho. Na gestão de pessoas, para o máximo sucesso da organização, é importante que todos os setores participem dos processos desenvolvidos, a fim de se estabelecer um processo produtivo contínuo e seguro (MACÊDO et al, 2012).

Se responsabilizar pela saúde e segurança do trabalhador é mais do que atender a normas oficiais, é também uma ferramenta de gestão para redução de custos, aumento da produção e qualidade de vida no meio ambiente de trabalho, pois uma organização funcionando dentro das normas representa menos problemas legais, menos burocracia e maior foco nas atividades internas.

\section{CONSIDERAÇÕES FINAIS}

Buscava-se debater a temática da responsabilidade das empresas para com a saúde e segurança dos trabalhadores em seu meio ambiente de trabalho. Com base na CLT, nos estudos de meio ambiente de trabalho e gestão de pessoas, é compreensível que a dinâmica organizacional ultrapassa a premissa do "faz-se porque é obrigatório" para "faz-se porque colabora com o crescimento da organização". Vai para além da responsabilidade legal.

Garantir os direitos à saúde e segurança no trabalho para todos ali presentes é uma medida que protege o empregado de possíveis mazelas e colabora para a qualidade de vida no meio ambiente de trabalho, gerando consequências positivas para a organização, com profissionais mais engajados e em melhores condições de saúde, significando menos custo com funcionário acidentado ou adoentado.

Apesar de toda essa concepção, ainda é preciso apontar a necessidade de se atualizar a CLT. As formas de organização do trabalho e meio ambientes internos são muito diferentes do que eram em 1943, quando as leis trabalhistas se consolidaram e, embora elas tenham acompanhado algumas mudanças com o tempo, ainda parece haver pontos antiquados e que se afastam da atual realidade tecnocientífica, como os trabalhados em home office e aqueles pagos por produtividade e não por carga horária.

O funcionário precisa se sentir protegido para mais do que a lei atribui aos ambientes de trabalho. É obrigação o respeito às NRs, é eficiência a empresa se prevenir de acidentes interno e promover a qualidade de vida em seu ambiente. As organizações têm responsabilidades com seus empregados e não podem ignorar isso, todavia é possível unir isto a práticas de promoção ao bem-estar dos funcionários, elevando o que seria apenas um cumprimento de lei a um patamar de gestão responsável.

\section{REFERÊNCIAS}

ABUD, S. M. R. Direito do trabalho. São Paulo: Barros, Fischer e associados, 2014.

BENATTI, M. C. C.; NISHIDE, V. M. Elaboração e implantação do mapa de riscos ambientais para prevenção de acidentes do trabalho em uma unidade de terapia intensiva de um hospital universitário. Rev.latinoam.enfermagem, Ribeirão Preto, v. 8, n. 5, p. 13-20, outubro, 2000.

BRASIL. Constituição da republica federativa do Brasil de 1988. Disponível em: < http://www.planalto.gov.br/ccivil_03/constituicao/consti tuicaocompilado.htm> Acesso em: 05 de Jun. 2017. 
Decreto-lei no 5.452. Consolidação das leis do trabalho.1을 de Maio de 1943.

Lei no 10.406 de 10 de Janeiro de 2002. Código

Civil. Disponível em: <

http://www3.dataprev.gov.br/sislex/paginas/11/2002/10

406.htm> Acesso em: 05 de Jun. 2017.

Portaria MTB no 3.214, de 08 de junho de 1978.

Normas regulamentadoras. Disponível em: < http://www010.dataprev.gov.br/sislex/paginas/63/mte/1 978/3214.htm> Acesso em: 29 de Mai. 2017.

CEREZO, M. C. UNO pré-vestibular semiextensivo. São Paulo: Moderna, 2007.

CHIAVENATO, Idalberto. Administração nos novos tempos. 13 ed. Rio de Janeiro: Campus, 1999.

Planejamento, recrutamento e seleção de pessoal: como agregar talentos à empresa. São Paulo: Manoele, 2009.

CHIUVITE, T. B. S. Resumão jurídico: direito ambiental. 2 ed. São Paulo: Barros, Fischer e associados, 2012.

DEJOURS, C. Banalização da injustiça social. São Paulo: FGV, 7.ed., 2007.

GARCIA, G. F. B. Meio ambiente do trabalho: direito, segurança e medicina do trabalho. 4 ed. São Paulo: Método, 2014.

GIL, A. C. Métodos e técnicas de pesquisa social. 6. ed. São Paulo: Atlas, 2014.

MARTINS, G. A.; LINTZ, A. Guia para elaboração de monografias e trabalhos de conclusão de curso. 2. ed., São Paulo: Atlas, 2011, p. 15.

GALON, T.; MARZIALE, M. H. P.; SOUZA, W. L. A legislação brasileira e as recomendações internacionais sobre a exposição ocupacional aos agentes biológicos. Revista Brasileira de Enfermagem, Brasília, n. 64, p. 160-167, janfev, 2011.

MACÊDO, I. I. et al. Gestão de Pessoas. Rio de Janeiro: FGV, 2012.

MELO, F. A. O. et al. A importância do recrutamento e seleção interna: um estudo de caso em uma instituição financeira de economia mista. Cadernos UniFOA, 17. ed., Dez., p. 73-87, 2011.

MELO, R. M. Responsabilidade civil pelos danos à saúde do trabalhador decorrentes da exposição à fumaça de cigarro. Revista TST, Brasília, vol. 78, n. 1, p. 238-257, jan/mar, 2012.

MINARDI, F. F. Meio ambiente do trabalhon proteção jurídica à saúde mental. Curitiba: Juruá Editora, 2010.

ROCHA, A. L. P. P. Melhores práticas em sistema de gestão de meio ambiente e meio ambiente do trabalho. Fórum de direito urbano e ambiental - FDUA. Belo Horizonte: Ano 1, n. 1, jan./fev., 2002.

SIRVINSKAS, L. P. Manual de direito ambiental. São Paulo:
Saraiva, 2010.

Submissão: 13/04/2020

Aprovado para publicação: 04/09/2020 